\title{
AMP-activated protein kinase inhibits NF- $K B$ signaling and inflammation: impact on healthspan and lifespan
}

\author{
Antero Salminen • Juha M. T. Hyttinen • \\ Kai Kaarniranta
}

Received: 18 January 2011 /Revised: 24 February 2011 / Accepted: 28 February 2011 / Published online: 23 March 2011

(C) The Author(s) 2011. This article is published with open access at Springerlink.com

\begin{abstract}
Adenosine monophosphate-activated protein kinase (AMPK) is a crucial regulator of energy metabolic homeostasis and thus a major survival factor in a variety of metabolic stresses and also in the aging process. Metabolic syndrome is associated with a low-grade, chronic inflammation, primarily in adipose tissue. A low-level of inflammation is also present in the aging process. There are emerging results indicating that AMPK signaling can inhibit the inflammatory responses induced by the nuclear factor- $\mathrm{kB}(\mathrm{NF}-\mathrm{kB})$ system. The NF$\mathrm{KB}$ subunits are not direct phosphorylation targets of AMPK, but the inhibition of NF- $\mathrm{KB}$ signaling is mediated by several downstream targets of AMPK, e.g., SIRT1, PGC- $1 \alpha$, p53, and Forkhead box O (FoxO) factors. AMPK signaling seems to enhance energy metabolism while it can repress inflammatory responses linked to chronic stress, e.g., in nutritional overload
\end{abstract}

\section{A. Salminen $(\bowtie)$}

Department of Neurology, Institute of Clinical Medicine,

University of Eastern Finland,

P.O. Box 1627, 70211, Kuopio, Finland

e-mail: antero.salminen@uef.fi

\section{A. Salminen}

Department of Neurology, Kuopio University Hospital, P.O. Box 1777, 70211, Kuopio, Finland

J. M. T. Hyttinen $\cdot$ K. Kaarniranta

Department of Ophthalmology, Institute of Clinical Medicine,

University of Eastern Finland,

P.O. Box 1627, 70211, Kuopio, Finland

J. M. T. Hyttinen

e-mail: juha.hyttinen@uef.fi

K. Kaarniranta

e-mail: kai.kaarniranta@uef.fi

K. Kaarniranta

Department of Ophthalmology, Kuopio University Hospital, P.O. Box 1777, 70211, Kuopio, Finland and during the aging process. AMPK can inhibit endoplasmic reticulum and oxidative stresses which are involved in metabolic disorders and the aging process. Interestingly, many target proteins of AMPK are so-called longevity factors, e.g., SIRT1, p53, and FoxOs, which not only can increase the stress resistance and extend the lifespan of many organisms but also inhibit the inflammatory responses. The activation capacity of AMPK declines in metabolic stress and with aging which could augment the metabolic diseases and accelerate the aging process. We will review the AMPK pathways involved in the inhibition of NF- $\mathrm{KB}$ signaling and suppression of inflammation. We also emphasize that the capacity of AMPK to repress inflammatory responses can have a significant impact on both healthspan and lifespan.

Keywords Aging $\cdot$ Diabetes $\cdot$ Inflammation $\cdot$ Metabolic syndrome $\cdot$ NF-kB $\cdot$ SIRT1

\section{Introduction}

The AMP-activated protein kinase (AMPK) is a crucial regulator of energy metabolic homeostasis at the cellular and whole organism levels [1-3]. AMPK is a serine/ threonine kinase which has been highly conserved during evolution. AMPK consists of a heterotrimeric complex including a catalytic $\alpha$ subunit and regulatory $\beta$ and $\gamma$ units. There are two isoforms of $\alpha(\alpha 1$ and $\alpha 2)$ and $\beta$ ( $\beta 1$ and $\beta 2)$ and three $\gamma$ subunits $(\gamma 1-3)$ which are differently expressed in mammalian tissues. AMPK is activated via allosteric regulation of increased AMP concentration and by the phosphorylation of $\alpha$ subunit (Thr172) via the upstream kinases serine/threonine kinase 11 (LKB1), Ca2+/ calmodulin-dependent protein kinase kinase $\beta(\mathrm{CaMKK} \beta)$, and transforming growth factor- $\beta$-activated kinase 1 . 
AMPK has a wide array of downstream substrates; these are typically energy metabolic enzymes and proteins involved in transcriptional regulation. One major role of AMPK signaling is to respond to metabolic requirements either by stimulating energy production including glucose and lipid catabolism or by inhibiting energy consuming pathways, e.g., synthesis of protein, fatty acids, and cholesterol. Impaired AMPK activity can induce insulin resistance in many tissues [3, 4]. It is not surprising that there are several observations linking deficiency in AMPK signaling to the appearance of the metabolic syndrome including obesity, diabetes, and cardiovascular diseases [2]. Currently, AMPK is an exciting research topic and the focus of intensive drug discovery projects. Several pharmacological AMPK activators have been identified, e.g., 5aminoimidazole-4-carboxamide riboside (AICAR), metformin, statins, thiazolidinediones, and several natural plant products $[2,5,6]$.

The AMPK signaling system plays a key role in cellular and organismal survival during stress by its ability to maintain metabolic homeostasis. Chronic nutrient overload and positive energy balance induce stress in adipose tissue. Accumulation of lipids in adipocytes as well as the ectopic storage of fat in liver, muscles, and pancreas stimulate the innate immunity defense leading to the secretion of proinflammatory cytokines and subsequently to recruitment of monocytes, especially into the adipose tissue [7-9]. There are several studies indicating that a low-grade, chronic inflammation has a crucial role in the development of the metabolic syndrome. Interestingly, there is emerging evidence that through its signaling network, AMPK can suppress the activation of nuclear factor- $\mathrm{KB}(\mathrm{NF}-\mathrm{kB})$ system, a key regulator of innate immunity and inflammation. We will review the signaling pathways of AMPK which are involved in the inhibition of NF- $\mathrm{KB}$ signaling and the suppression of inflammatory responses. We will emphasize that the capacity of AMPK to repress the appearance of a proinflammatory phenotype can has a major impact on both healthspan and lifespan.

\section{AMPK: repressor of inflammation}

Innate and adaptive immunity are the major host defense mechanisms which not only can provoke inflammation in order to protect organism against invading pathogens but also repair tissue injuries and alert the immune system from jeopardizing cellular damage. Inflammation is a crucial survival mechanism but it can be dangerous if it becomes overwhelming or if it is converted to a chronic state. Several metabolic disorders, e.g., obesity, type 2 diabetes, and atherosclerosis, trigger immune defense mechanisms and induce chronic inflammation which in turn aggravates the symptoms of the disease $[7,10,11]$. The endoplasmic reticulum (ER) is a sensitive nutrient sensor, e.g., unfolded protein response (UPR) becomes activated in response to hyperglycemia and fatty acid overload [12]. ER stress can generate an inflammatory response via different signaling pathways [10, 13, 14]. Hotamisligil [10] has recently reviewed the role of ER stress in the induction of lowgrade, chronic inflammation associated with metabolic diseases. Oxidative stress is another major stress condition present in the metabolic syndrome [15] and aging [16] which can stimulate inflammatory responses [17].

There is an extensive literature describing how the activation of AMPK can inhibit inflammatory response induced by different stimulating insults whereas a decrease in AMPK activity is associated with increased inflammation. Several studies have demonstrated that the activation of AMPK by AICAR can inhibit, e.g., acute and chronic colitis [18], autoimmune encephalomyelitis [19], inflammation in cystic fibrosis [20], and proinflammatory effects after lung injury [21]. It has also been observed that the therapeutic drug which is an AMPK agonist, metformin, can reduce the systemic inflammation by decreasing the level of C-reactive protein and interleukin-6 (IL-6) in mild metabolic syndrome [22]. Metformin can also lower plasma macrophage migration inhibitory factor concentrations in obese patients [23]. Many in vitro experiments have demonstrated that the lipopolysaccharide (LPS)-induced inflammatory response can be inhibited by activating AMPK with AICAR [18, 21, 24]. However, some recent observations imply that AICAR can also inhibit inflammatory responses via AMPK-independent pathways [25].

Several studies have revealed a close link between the reduced AMPK activity and inflammation, e.g., in adipose tissue and macrophages [26-29]. Steinberg et al. [30] observed that tumor necrosis factor- $\alpha$ (TNF- $\alpha$ ) suppressed the activity of AMPK by upregulating the expression of protein phosphatase $2 \mathrm{C}$, an inhibitor of AMPK signaling. The reduced AMPK activity decreased fatty acid oxidation, increased diacylglycerol accumulation, and induced insulin resistance in skeletal muscle [30]. Ko et al. [28] demonstrated that nutrient stress induced by high-fat feeding reduced cardiac AMPK activity and triggered inflammation reflected in an increased number of macrophages and upregulation of IL-6 levels in the mouse heart. In addition, they revealed that acute infusion of IL-6 profoundly decreased the activity of AMPK, reduced the myocardial glucose uptake, and triggered inflammation in the heart. They also observed that diet-induced cardiac insulin resistance and the level of inflammation were attenuated in IL-6-deficient mice [28]. However, there are observations that IL-6 knockout mice can develop mature-onset obesity [31] and display an enhanced formation of dietinduced atherosclerosis [32]. This could be linked to the 
reduced AMPK activity in IL-6 knockout mice [33], but there may be tissue-specific changes in diet-induced responses between heart and adipose/vascular tissues, in particular, in chronic knockout conditions. Yang et al. [27] demonstrated that inflammatory stimuli and a fatty acid rich-diet decreased the expression and activity of $\alpha 1$ AMPK in mouse adipose tissue and macrophages and triggered TNF- $\alpha$ expression. The AICAR treatment could reverse the LPS and diet-induced inflammation. Sag et al. [29] observed that IL-10 and transforming growth factor- $\beta$ (TGF- $\beta$ ), two anti-inflammatory cytokines, stimulated a rapid phosphorylation and activation of AMPK whereas a proinflammatory insult with LPS decreased the AMPK activity in mouse and human macrophages. These experiments indicate that the activity of AMPK regulates the inflammatory responses and consequently can induce insulin resistance in different tissues.

There are several physiological inducers of AMPK activity including many hormones, e.g., adiponectin and leptin [34], dietary phytochemicals, e.g. resveratrol, curcumin, and berberine [35], and physical exercise [36] (Fig. 1). Interestingly, many of these stimuli are linked to the inhibition of inflammatory responses. For instance, adiponectin has many anti-inflammatory, antiatherogenic, and antidiabetic properties [37]. Aggarwal [38] has reviewed the anti-inflammatory effects of curcumin and its capacity to reverse insulin resistance, hyperglycemia, and hyperlipidemia linked to obesity. Resveratrol is also a potent antiinflammatory compound [39] activating AMPK-SIRT1 (silent information regulator 1) pathway (see below).

\section{AMPK inhibits NF-KB signaling via several pathways}

The NF- $\mathrm{kB}$ signaling system is the principal pathway which is involved in the activation of both the innate and adaptive immune systems [40]. A plethora of studies have demonstrated that the activation of AMPK signaling downregulates the function of NF-kB system [18, 27, 29, 41-43]. AMPK has several direct phosphorylation targets [1], but it seems that AMPK suppresses NF-KB signaling indirectly via its downstream mediators, e.g., SIRT1, Forkhead box $\mathrm{O}$ (FoxO) family, and peroxisome proliferator-activated receptor $\gamma$ co-activator $1 \alpha$ (PGC$1 \alpha$ ), which can subsequently repress the expression of inflammatory factors (Fig. 1). Moreover, there is an extensive literature indicating that activation of AMPK inhibits the NF- $\mathrm{KB}$-mediated proinflammatory signaling whereas it can activate the NF- $\mathrm{kB}$ system in order to stimulate the expression of antiapoptotic proteins, e.g., Bcl-2 and survivin [44]. Cacicedo et al. [45] observed that AMPK activation inhibits NF-kB transactivation induced by TNF- $\alpha$ and fatty acid palmitate in endothelial cells. In addition,

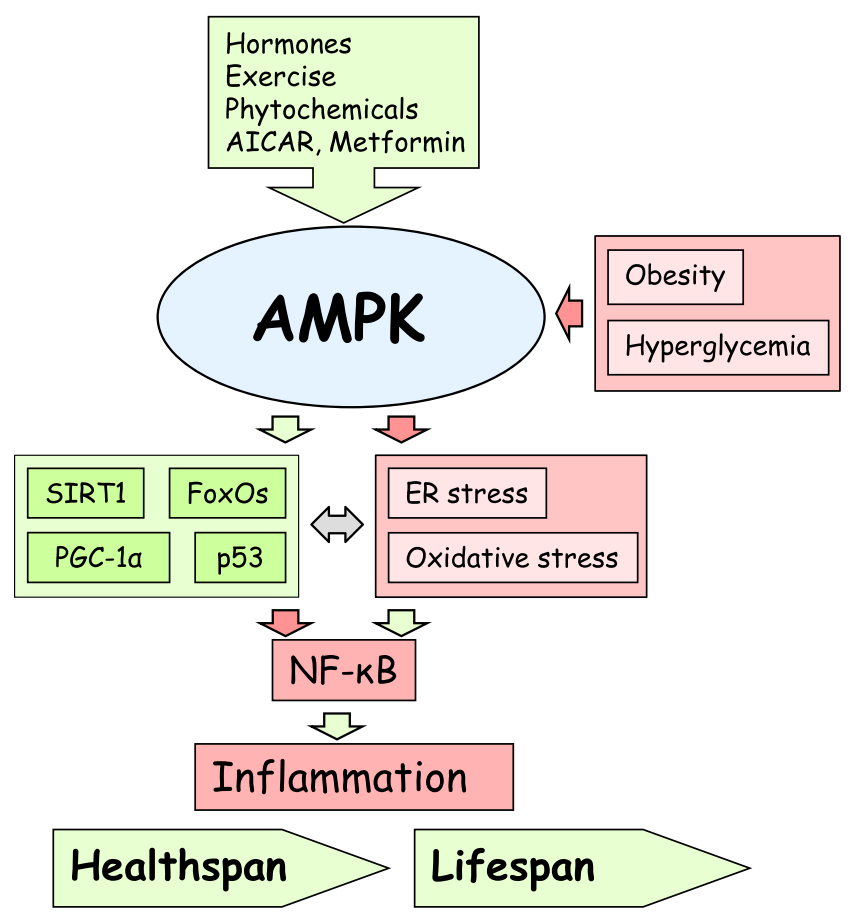

Fig. 1 Schematic illustration of the functional connections of AMPK linked to the inhibition of NF-KB signaling and suppression of inflammation. Green arrows show the activating pathways and red arrows are the inhibitory connections. Several hormones and phytochemicals, physical exercise, and some drugs, e.g., AICAR and metformin, activate AMPK. In contrast, obesity and hyperglycemia inhibit the expression of AMPK. On the downstream, AMPK stimulates SIRT1, PGC-1 $\alpha$, p53, and FoxO factors which can inhibit the NF-kB signaling with different mechanisms. AMPK inhibits the appearance of ER and oxidative stresses which can trigger NF- $\mathrm{KB}$ signaling. NF- $\mathrm{KB}$ is the key inducer of inflammatory responses which affect the healthspan and lifespan

calcium entry into endothelial cells stimulates CaMKK $\beta$, one of the upstream activators of AMPK [1], and subsequently, AMPK activates the NF-KB system via protein kinase $\mathrm{C} \delta$ and p38MAPK signaling [46]. These observations indicate that there are multiple downstream signaling pathways through which AMPK can regulate a number of different gene arrays, e.g., those regulating metabolic events, cell cycle and differentiation, and inflammatory responses.

Although AICAR and metformin are not specific AMPK activators, these compounds have been used in many inflammatory studies to demonstrate that AMPK can inhibit $\mathrm{NF}-\mathrm{KB}$ signaling. However, there are a number of studies in which the AMPK subunits have been specifically inhibited by short hairpin RNA knockdown technique or expression of dominant-negative AMPK components. For instance, Huang et al. [47] demonstrated that the knockdown of $\alpha 1 \mathrm{AMPK}$ abolished the anti-inflammatory effect of metformin. Yang et al. [27] revealed that the constitutively active $\alpha 1 \mathrm{AMPK}$ suppressed the NF-KB signaling and fatty acid-induced inflammation in macrophages and that dominant-negative 
$\alpha 1$ AMPK could reverse the inhibition. Katerelos et al. [48] have observed that the overexpression of $\alpha 1 \mathrm{AMPK}$ reduced $\mathrm{NF}-\mathrm{KB}$ signaling in aortic endothelial cells. AICAR induced similar effects as the activation of $\alpha 1$ AMPK. Wang et al. [41] demonstrated that the NF-KB signaling was activated in the aortic endothelial cells isolated from AMPK $\alpha 2$ knockout mice whereas AMPK activation by AICAR and constitutively active AMPK $\alpha 2$ had an opposite effect.

\section{AMPK-SIRT1-NF-kB signaling}

AMPK and SIRT1 are evolutionary conserved partners which have similar functions in metabolism and cellular survival [49]. Canto et al. [50] demonstrated that AMPK can activate SIRT1 deacetylase by increasing cellular $\mathrm{NAD}^{+}$levels. SIRT1, type III deacetylase, has several target proteins which regulate many host defense functions. Conversely, SIRT1 can stimulate the activity of LKB1, which subsequently activates AMPK [51]. This represents a positive feedback loop to enhance cellular survival during energy deficiency. Yeung et al. [52] were the first researchers who demonstrated that SIRT1 could interact with the RelA/p65 subunit of NF-KB complex and consequently deacetylates the $\mathrm{p} 65$ protein at lysine 310 . The acetylation of $\mathrm{p} 65$ enhances the transactivation capacity of the NF- $\mathrm{kB}$ complex, and thus, SIRT1-induced deacetylation inhibits NF- $\mathrm{kB}$ signaling (Fig. 1). Recently, Yang et al. [53] observed that the deacetylation of lysine 310 at p65 component enhanced the Set9-mediated methylation of lysines 314 and 315 and triggered the ubiquitination and degradation of the p65 subunit of NF- $k B$. There are many reports that SIRT1 can repress inflammatory responses via inhibition of NF-KB signaling $[27,54,55]$. Several dietary polyphenols can activate AMPK and SIRT1, and it seems that their antiinflammatory effects are mediated via the AMPK/SIRT1induced p65 deacetylation [56]. We have recently reviewed the role of SIRT1-NF-kB signaling pathway in the suppression of immune responses, e.g., in human immunodeficiency virus-1 infection [57].

\section{AMPK-NF-kB/PGC- $1 \alpha$ signaling}

PGC- $1 \alpha$ is one of the key regulators of energy metabolism, e.g., enhancing glycolysis and mitochondrial biogenesis [58]. AMPK phosphorylates PGC- $1 \alpha$ protein which triggers SIRT1-mediated deacetylation and activation of PGC- $1 \alpha$. Alvarez-Guardia et al. [59] demonstrated that PGC- $1 \alpha$ could bind to the p65 subunit of NF- $\mathrm{kB}$ in human cardiac cells and mouse heart. They also observed that the activation of NF$\mathrm{KB}$ signaling increased the interaction between $\mathrm{p} 65$ and PGC- $1 \alpha$ which consequently reduced the expression of PGC- $1 \alpha$ protein. This is an important observation since it may explain why activation of NF-kB system, e.g., via inflammatory cytokines, has such profound effects on metabolism promoting the appearance of metabolic disorders. Moreover, Morari et al. [60] observed that fatty acids can induce the association of $\mathrm{PGC} 1 \alpha$ factor with the p50 component of NF-KB complex in hepatocytes. They also detected that PGC-1 $\alpha$ and p50 could bind to the IL-10 promoter and induce the expression of IL-10 cytokine. IL-10 is the protective cytokine against diet-induced liver inflammation. These first two studies imply that the physical interaction of PGC- $1 \alpha$ and NF-KB complexes may be situated at crossroads in the regulation of energy metabolism and inflammation although the reciprocal regulation of PGC$1 \alpha$ and NF-KB system still needs to be confirmed. Kim et al. [61] demonstrated that the increased expression of PGC$1 \alpha$ could inhibit the NF-KB activity and the proinflammatory response induced by TNF- $\alpha$ in human aortic smooth muscle and endothelial cells (Fig. 1). Palomer et al. [62] observed that the cardiac-specific overexpression of TNF- $\alpha$ in the transgenic mouse significantly downregulated PGC- $1 \alpha$ expression and induced cardiomyopathy. There are cell culture experiments demonstrating a crucial decrease in PGC- $1 \alpha$ expression being mediated by NF- $\mathrm{KB}$ and p38MAPK signaling [62].

\section{AMPK-p53/FoxO signaling}

The FoxO family and p53 are evolutionary conserved transcription factors which are involved in a variety of different functions including the regulation of energy metabolism [63, 64] and inflammation [65, 66]. Jones et al. [67] demonstrated that AMPK phosphorylated p53 protein at serine 15 a modification which could trigger AMPK-dependent cell cycle arrest. The p53 and NF-kB signaling have many antagonistic functions, e.g., p53 can inhibit NF-KB signaling $[68,69]$. It is known that $\mathrm{p} 53$ is a potent inhibitor of glycolysis whereas it increases aerobic respiration [63]. Kawauchi et al. [70] observed that the lack of p53 protein expression clearly increased the rate of glycolysis and significantly stimulated the activity of NF- $\mathrm{kB}$ signaling. Increased glycolytic activity promotes the $\mathrm{O}$ glycosylation of IKB kinase-beta (IKK $\beta$ ) at serine 733 . This modification blocks the inactivating feedback phosphorylation site at IKK $\beta$ and in that way it can enhance the activity of IKK $\beta$ which accordingly triggers NF-KB signaling [71]. It seems that glycolysis is not the only connection which links p53 to the inhibition of inflammation (Fig. 1). Komarova et al. [66] have demonstrated that the functional activities of $\mathrm{NF}-\mathrm{KB}$ were increased in the p53-null mice including the potentiated responses to inflammatory insults. AMPK can target the serine 15 and 20 sites in the transactivation domain of $\mathrm{p} 53$ protein $[67,72]$. Both of these phosphorylation sites are linked to the inflammation [73] and aging processes [72] though the exact molecular mechanisms need to be clarified. 
The mammalian FoxO family consists of FOXO1, FOXO3a, FOXO4, and FOXO6 transcription factors which can regulate several processes, e.g., stress resistance, glucose metabolism, and inflammation [64, 65]. In Caenorhabditis elegans, the AMPK-FoxO pathway has a crucial role in the caloric restriction induced lifespan extension [74]. Greer et al. [75] demonstrated that the mammalian AMPK can phosphorylate FOXO3a at six regulatory sites and this will activate the transcription of a specific set of genes. Currently, it is not known whether there are differences in the activation levels of separate FoxO factors, in particular, in different tissues. However, Lin et al. [76] revealed that the FOXO3a deficiency in mice induced inflammatory responses in several tissues and lymphoid proliferation. Helper $\mathrm{T}$ cells were hyperactivated and produced more Th1 and Th2 cytokines than their wildtype counterparts. They also observed that FOXO3 inhibited the NF- $\mathrm{KB}$ activity in $\mathrm{T}$ cells and the lack of FOXO3a generated the autoinflammatory condition in these mice. Zhou et al. [77] demonstrated that also FOXO4 was an endogenous inhibitor of NF- $\mathrm{KB}$ and a deficiency of FOXO4 could induce colonic inflammation and injury in mice. Interestingly, mammalian SIRT1 bound to FOXO4 and increased its transactivation capacity by NADdependent deacetylation [78]. These results indicate that AMPK can regulate the function of FoxO factors either by direct phosphorylation or indirectly via the SIRT1-induced activation.

\section{AMPK inhibits ER and oxidative stresses}

There are several studies indicating that the activation of AMPK represses the oxidative stress triggered by different insults, e.g., hyperglycemia and fatty acids [41, 79-81] (Fig. 1). Xie et al. [80] observed that AMPK signaling induced the expression of mitochondrial uncoupling protein2 (UCP-2) and in that way clearly reduced the production of superoxide radicals in hyperglycemic endothelial cells. It is known that UCP-2 is able to inhibit the mitochondrial reactive oxygen species (ROS) production. Moreover, Wang et al. [41] demonstrated using different techniques that AMPK $\alpha 2$ is the physiological suppressor of the ROS produced via $\mathrm{NAD}(\mathrm{P}) \mathrm{H}$ oxidase. Their results support the mechanism whereby AMPK inhibits the NF- $\mathrm{KB}$ signaling and thus downregulates the expression of different $\mathrm{NAD}(\mathrm{P}) \mathrm{H}$ oxidase subunits and thus alleviates oxidative stress. Recently, Li et al. [79] revealed that AMPK signaling via the AMPKFOXO3 pathway induced the expression of thioredoxin (Trx), a disulfide reductase which protects cellular proteins against cysteine oxidation. The function of $\operatorname{Trx}$ can be inhibited in cells by binding of the thioredoxin-interacting protein (Txnip). Oxidative stress, e.g., such as that occurring in hyperglycemia, is a potent inducer of the expression of
Txnip which subsequently inhibits the activity of Trx and exposes cells to the effects of oxidative stress [81]. Interestingly, Zhou et al. [17] demonstrated that Txnip could interact with inflammasomal receptor Nod-like receptor protein 3 (NLRP3). Oxidative stress dissociated the complex between Trx and Txnip which subsequently could bind to the NLRP3 receptor and in that way activate the inflammasomal multiprotein complex. Inflammasomes cleave the pro-IL-1 $\beta$ and pro-IL-18 precursors to the active cytokines which can trigger the expression of a variety of inflammatory factors. Increased expression of Trx via the AMPK signaling can prevent the inflammasomal activity which is increased in many metabolic diseases.

The endoplasmic reticulum (ER) is a sensitive stress sensor in the maintenance of cellular protein quality and nutrient balance [12, 82]. Oxidative stress impairs homeostasis in ER and leads to protein misfolding in ER and calcium release into the cytoplasm. ER stress triggers a set of transducer proteins that stimulate the unfolded protein response (UPR) [82]. Recent studies have revealed that the UPR involves the activation of NF- $\mathrm{KB}$ system which can trigger a low-grade inflammatory response [10, 13, 14]. Several studies have reported that AMPK activity can attenuate the ER stress, e.g., in oxidized LDL-exposed aortic endothelial cells [83] and in hypoxic cardiomyocytes [84]. Dong et al. [85] demonstrated that the deletion of AMPK $\alpha 2$ increased ER stress in endothelial cells and caused aortic lesions in the knockout mice. They also noted that several antioxidants were able to suppress the appearance of ER stress. This indicates that ER stress is provoked by oxidative stress induced by the deletion of AMPK $\alpha 2$.

\section{Significance of anti-inflammatory potency of AMPK}

Current lifestyle including caloric overload and minimal level of physical exercise has created an epidemic of obesity and metabolic syndrome. A plethora of studies have revealed that nutritional excess is linked to a lowgrade, metabolic inflammation, particularly in the adipose tissue, and there is clear evidence that inflammation has a key role in the progression of metabolic diseases [7-9]. AMPK is the master regulator of energy homeostasis, and it can also inhibit the NF- $\mathrm{KB}$ signaling and thus prevent the appearance of a proinflammatory phenotype during aging process itself and in several age-related diseases (Fig. 1). There are extensive reviews concerning the role of AMPK in type II diabetes and metabolic syndrome [86, 87], cardiovascular diseases [88, 89], and cancer [90]. All of these diseases involve the presence of inflammation, but currently, the role of AMPK in the prevention of inflammatory responses needs to be clarified. 
The overload of adipose tissue with fatty acids induces a stress response in adipocytes, i.e., oxidative stress and ER stress, which can trigger inflammatory reactions via the NF$\mathrm{KB}$ signaling and inflammasomal activation [10, 17]. Moreover, the increased fatty acid concentration can inhibit the AMPK activity by stimulating protein phosphatase $2 \mathrm{~A}$ [91]. Hyperglycemia can also generate oxidative stress and activate NF-KB signaling. As described above, AMPK signaling can repress ROS production [41] and increase the expression of thioredoxin which is a potent inhibitor of inflammasomal activation [17, 79]. AMPK activity can also reduce the level of ER stress and thus suppress inflammatory responses and improve healthspan [83-85]. AMPK can also repress inflammatory responses via SIRT1 [27, 55], PGC-1 $\alpha[61,62]$, and FoxO [76, 77] signaling (see above). Emerging results in mouse models indicate that the activation of SIRT1 can effectively prevent the appearance of age-related pathologies [92]. In addition, the LKB1AMPK signaling is a powerful tumor suppressor pathway, and there are therapeutic implications that AMPK agonists could be potent cancer drugs [90, 93].

AMPK activity can support the adaptive capabilities of cells by enhancing the biogenesis of mitochondria [94]. Mitochondrial dysfunction is associated with the aging process and age-related degenerative diseases. For instance, impaired mitochondria release damage-associated molecules which can stimulate systemic inflammatory response [95]. Zhang et al. [96] demonstrated that the LPS-induced systemic inflammation was linked to a fast and strong downregulation of the AMPK expression in blood leukocytes and liver. Recently, Zhou et al. [97] observed that mitochondria are the source of ROS release that stimulates inflammasomes and triggers the secretion of IL-1 $\beta$ and IL-18. Inflammasomes are activated in several obesity-related diseases, e.g., type II diabetes and cardiovascular diseases [98, 99]. It seems that AMPK can regulate inflammasomal activation by (1) stimulating autophagy and cleansing dysfunctional mitochondria [100] or (2) inhibiting NF- $k B$ activation which is a priming phase in the activation of inflammasomes [101].

Exercise is a potent activator of AMPK signaling, in particular, in skeletal muscles and also in heart, liver, and adipose tissue [36]. The activation of AMPK during exercise is important for energy production, but it seems that several beneficial effects of exercise on healthspan could be induced by AMPK signaling pathways [36]. In addition, many hormones, e.g., adiponectin and leptin [34], can stimulate AMPK signaling (Fig. 1). Adiponectin, in particular, the high molecular weight isoform of the hormone, is a potent physiological activator of AMPK which inhibits NF-kB signaling and inflammatory response in endothelial cells [101]. These observations underline the significance of AMPK in prevention in vivo against inflammation. Currently, AMPK is an important drug design target in order to find specific agonists [6]. Metformin is a clinically used AMPK agonist against hyperglycemia in type II diabetes, and it is also a potent anticancer drug in certain types of cancers [102]. Metformin can inhibit NF-KB signaling and repress inflammatory responses (see above) and thus also alleviate the metabolic syndrome. Zhou et al. [87] have reviewed the current status in the drug development of small molecule AMPK activators.

Several research approaches have revealed that the aging process is associated with a low-grade inflammation [103105]. The inflammatory phenotype is linked to the activation of NF- $\mathrm{kB}$ system in several tissues during aging [104-107]. Interestingly, many observations have indicated that the activation capacity of AMPK declines with aging which seems to be linked to the reduced stress resistance [108-110]. Confirming the role of AMPK in the aging process, many studies in C. elegans have demonstrated that the AAK-2, the nematode analog of AMPK, is a crucial factor involved in the lifespan extension induced by the overexpression of SIR-2.1 (analog of SIRT1) and mitochondrial manipulation [111, 112]. AAK-2 also regulates energy metabolism during the dauer state of $C$. elegans [112]. Recently, Selman et al. [113] observed that the extension of lifespan in ribosomal protein S6 kinase 1deficient mice was most likely linked to the increased activation of AMPK since these mice displayed a strong overlap in the gene expression patterns with those induced by AICAR treatment. Several observations indicate that the autophagic capacity declines during aging [114] which could be caused by the reduced activation of AMPK [108110]. Interestingly, SIRT1 is a potent activator of autophagy [115] and the activation of SIRT1, e.g., by resveratrol, could stimulate autophagic uptake of damaged mitochondria. Bauer et al. [116] demonstrated that resveratrol could enhance the healthspan and extend the lifespan of mice consuming a high-calorie diet. In conclusion, many longevity factors, e.g., SIRT1, p53, and FoxOs, are associated with the activation of AMPK signaling and subsequently can inhibit inflammation [117] but, in addition, activate autophagic housekeeping and maintain cellular energy status, and in that way, AMPK signaling is able to improve the healthspan, prevent age-related diseases, and extend the lifespan.

\section{Concluding remarks}

Many studies have demonstrated that AMPK activity can inhibit inflammatory responses in diverse types of cells and tissues. The inhibition is mediated by several transcription factors which are the downstream targets of AMPK signaling, of these, SIRT1, PGC- $1 \alpha$, p53, and FoxOs are the best characterized. AMPK can also repress inflammatory 
responses triggered by endoplasmic reticulum and oxidative stresses. These studies indicate that AMPK can regulate both the energy metabolism and inflammatory defense. Interestingly, the AMPK activity is decreased in obesity and the metabolic syndrome, and this may enhance the activation of NF-KB signaling and the appearance of a low-grade, metabolic inflammation, e.g., in the adipose tissue. Currently, it is not known how ubiquitous this connection between the AMPK activity and NF- $\mathrm{kB}$ inhibition will be since there are different AMPK isoforms and the regulation clearly seems to be tissue specific. The NF-KB signaling is an important metabolic regulator in the hypothalamus and pancreatic beta cells, but whether this is linked to AMPK activity in the metabolic syndrome still needs to be clarified. A low-grade inflammation is also observed during aging in several tissues. However, it is not known whether the aging process and overnutrition induce a similar proinflammatory phenotype. Emerging evidence indicates that the overexpression of AMPK can delay the aging process, and surprisingly, AMPK can enhance the signaling of several longevity factors, e.g., SIRT1, p53, and FoxOs, which are involved in the inhibition of AMPK-mediated inflammation. Moreover, the prevalence of obesity and metabolic syndrome increases with aging which could support the concept that a dysfunction of AMPK is involved in aging and the metabolic syndrome.

Acknowledgments This study was financially supported by grants from the Academy of Finland and the University of Eastern Finland, Kuopio, Finland. The authors thank Dr. Ewen MacDonald for checking the language of the manuscript.

Disclosure of potential conflicts of interests The authors declare no conflicts of interests related to this work.

Open Access This article is distributed under the terms of the Creative Commons Attribution Noncommercial License which permits any noncommercial use, distribution, and reproduction in any medium, provided the original author(s) and source are credited.

\section{References}

1. Canto C, Auwerx J (2010) AMP-activated protein kinase and its downstream transcriptional pathways. Cell Mol Life Sci 67:34073423

2. Steinberg GR, Kemp BE (2009) AMPK in health and disease. Physiol Rev 89:1025-1078

3. Lage R, Dieguez C, Vidal-Puig A, Lopez M (2008) AMPK: a metabolic gauge regulating whole-body energy homeostasis. Trends Mol Med 14:539-549

4. Ruderman NB, Cacicedo JM, Itani S, Yagihashi N, Saha AK, Ye JM, Chen K, Zou M, Carling D, Boden G, Cohen RA, Keany J, Kraegen EW, Ido Y (2003) Malonyl-CoA and AMPK-activated protein kinase (AMPK): possible links between insulin resistance in muscle and early endothelial cell damage in diabetes. Biochem Soc Trans 31:202-206

5. Sun W, Lee TS, Zhu M, Gu C, Wang Y, Zhu Y, Shyy JYJ (2006) Statins activate AMP-activated protein kinase in vitro and in vivo. Circulation 114:2655-2662

6. Fogarty S, Hardie DG (2010) Development of protein kinase activators: AMPK as a target in metabolic disorders and cancer. Biochim Biophys Acta 1804:581-591

7. Hummasti S, Hotamisligil GS (2010) Endoplasmic reticulum stress and inflammation in obesity and diabetes. Circ Res 107:579-591

8. Maury E, Brichard SM (2010) Adipokine dysregulation, adipose tissue inflammation and metabolic syndrome. Mol Cell Endocrinol 314:1-16

9. Gustafson B (2009) Adipose tissue, inflammation and atherosclerosis. J Atheroscler Thromb 17:332-341

10. Hotamisligil GS (2010) Endoplasmic reticulum stress and the inflammatory basis of metabolic disease. Cell 140:900-917

11. Hotamisligil GS, Erbay E (2008) Nutrient sensing and inflammation in metabolic diseases. Nat Rev Immunol 8:923-934

12. Mandl J, Meszaros T, Banhegyi G, Hunyady L, Csala M (2009) Endoplasmic reticulum: nutrient sensor in physiology and pathology. Trends Endocrinol Metab 20:194-201

13. Salminen A, Kauppinen A, Suuronen T, Kaarniranta K, Ojala J (2009) ER stress in Alzheimer's disease: a novel neuronal trigger for inflammation and Alzheimer's pathology. J Neuroinflammation 6:41

14. Zhang K, Kaufman RJ (2008) From endoplasmic-reticulum stress to the inflammatory response. Nature 454:455-462

15. Roberts CK, Sindhu KK (2009) Oxidative stress and metabolic syndrome. Life Sci 84:705-712

16. Beckman KB, Ames BN (1998) The free radical theory of aging matures. Physiol Rev 78:547-581

17. Zhou R, Tardivel A, Thorens B, Choi I, Tschopp J (2010) Thioredoxin-interacting protein links oxidative stress to inflammasome activation. Nat Immunol 11:136-140

18. Bai A, Ma AG, Yong M, Weiss CR, Ma Y, Guan Q, Bernstein CN, Peng Z (2010) AMPK agonist downregulates innate and adaptive immune responses in TNBS-induced murine acute and relapsing colitis. Biochem Pharmacol 80:1708-1717

19. Nath N, Giri S, Prasad R, Salem ML, Singh AK, Singh I (2005) 5-aminoimidazole-4-carboxamide ribonucleoside: a novel immunomodulator with therapeutic efficacy in experimental autoimmune encephalomyelitis. J Immunol 175:566-574

20. Myerburg MM, King JD Jr, Oyster NM, Fitch AC, Magill A, Baty CJ, Watkins SC, Kolls JK, Pilewski JM, Hallows KR (2010) AMPK agonists ameliorate sodium and fluid transport and inflammation in cystic fibrosis airway epithelial cells. Am J Respir Cell Mol Biol 42:676-684

21. Zhao X, Zmijewski JW, Lorne E, Liu G, Park YJ, Tsuruta Y, Abraham E (2008) Activation of AMPK attenuates neutrophil proinflammatory activity and decreases the severity of acute lung injury. Am J Physiol Lung Cell Mol Physiol 295:L497-504

22. Akbar DH (2003) Effect of metformin and sulfonylurea on Creactive protein level in well-controlled type 2 diabetes with metabolic syndrome. Endocr 20:215-218

23. Dandona P, Aljada A, Ghanim H, Mohanty P, Tripathy C, Hofmeyer D, Chaudhuri A (2004) Increased plasma concentration of macrophage migration inhibitory factor (MIF) and MIF mRNA in mononuclear cells in the obese and suppressive action of metformin. J Clin Endocrinol Metab 89:5043-5047

24. Giri S, Nath N, Smith B, Viollet B, Singh AK, Singh I (2004) 5aminoimidazole-4-carboxamide-1- $\beta$-4-ribofuranoside inhibits proinflammatory response in glial cells: a possible role of AMP-activated protein kinase. J Neurosci 24:479-487

25. Labuzek K, Liber S, Gabryel B, Okopien B (2010) AICAR (5aminoimidazole-4-carboxamide-1- $\beta$-4-ribofuranoside) increases the production of toxic molecules and effects the profile of 
cytokines release in LPS-stimulated rat primary microglial cultures. Neurotoxicology 31:134-146

26. Gauthier MS, O’Brien EL, Bigornia S, Mott M, Cacicedo JM, Xu XJ, Gokce N, Apovian C, Ruderman N (2011) Decreased AMPactivated protein kinase activity is associated with increased inflammation in visceral adipose tissue and with whole-body insulin resistance in morbidly obese humans. Biochem Biophys Res Commun 404:382-387

27. Yang Z, Kahn BB, Shi H, Xue B (2010) Macrophage $\alpha 1$ AMPactivated protein kinase ( $\alpha 1 \mathrm{AMPK})$ antagonizes fatty acid-induced inflammation through SIRT1. J Biol Chem 285:19051-19059

28. Ko HJ, Zhang Z, Jung DY, Jun JY, Ma Z, Jones KE, Chan SY, Kim JK (2009) Nutrient stress activates inflammation and reduces glucose metabolism by suppressing AMP-activated protein kinase in the heart. Diabetes 58:2536-2546

29. Sag D, Carling D, Stout RD, Suttles J (2008) Adenosine 5'monophosphate-activated protein kinase promotes macrophage polarization to an anti-inflammatory functional phenotype. J Immunol 181:8633-8641

30. Steinberg GR, Michell BJ, van Denderen BJW, Watt MJ, Carey AL, Fam BC, Andrikopoulos S, Proietto J, Gorgun CZ, Carling D, Hotamisligil GS, Febbraio MA, Kay TW, Kemp BE (2006) Tumor necrosis factor $\alpha$-induced skeletal muscle insulin resistance involves suppression of AMP-kinase signaling. Cell Metab 4:465474

31. Wallenius V, Wallenius $\mathrm{K}$, Ahren B, Rudling M, Carlsten $\mathrm{H}$, Dickson SL, Ohlsson C, Jansson JO (2002) Interleukin-6deficient mice develop mature-onset obesity. Nat Med 8:75-79

32. Madan M, Bishayi B, Hoge M, Amar S (2008) Atheroprotective role of interleukin-6 in diet- and/or pathogen-associated atherosclerosis using an ApoE heterozygote murine model. Atherosclerosis 197:504-514

33. Kelly M, Keller C, Avilucea PR, Keller P, Luo Z, Xiang X, Giralt M, Hidalgo J, Saha AK, Pedersen BK, Ruderman NB (2004) AMPK activity is diminished in tissues of IL-6 knockout mice: the effect of exercise. Biochem Biophys Res Commun 320:449-454

34. Lim CT, Kola B, Korbonits M (2010) AMPK as a mediator of hormonal signalling. J Mol Endocrinol 44:87-97

35. Hwang JT, Kwon DY, Yoon SH (2009) AMP-activated protein kinase: a potential target for the diseases prevention by natural occurring polyphenols. N Biotechnol 26:17-22

36. Richter EA, Ruderman NB (2009) AMPK and the biochemistry of exercise: implications for human health and disease. Biochem J 418:261-275

37. Sun Y, Xun K, Wang C, Zhao H, Bi H, Chen X, Wang Y (2009) Adiponectin, an unlocking adipocytokine. Cardiovasc Ther 27:59-75

38. Aggarwal BB (2010) Targeting inflammation-induced obesity and metabolic diseases by curcumin and other nutraceuticals. Annu Rev Nutr 30:173-199

39. Das S, Das DK (2007) Anti-inflammatory responses of resveratrol. Inflamm Allergy Drug Targets 6:168-173

40. Vallabhapurapu S, Karin M (2009) Regulation and function of $\mathrm{NF}-\mathrm{kB}$ transcription factors in the immune system. Annu Rev Immunol 27:693-733

41. Wang S, Zhang M, Liang B, Xu J, Xie Z, Liu C, Viollet B, Yan D, Zou MH (2010) AMPK $\alpha 2$ deletion causes aberrant expression and activation of $\mathrm{NAD}(\mathrm{P}) \mathrm{H}$ oxidase and consequent endothelial dysfunction in vivo. Role of $26 \mathrm{~S}$ proteasomes. Circ Res 106:1117-1128

42. Wu X, Mahadev K, Fuchsel L, Ouedraogo R, Xu S, Goldstein BJ (2007) Adiponectin surrresses IKB kinase activation induced by tumor necrosis factor- $\alpha$ or high glucose in endothelial cells: role of cAMP and AMP kinase signaling. Am J Physiol Endocrinol Metab 293:E1836-1844

43. Hattori Y, Suzuki K, Hattori S, Kasai K (2006) Metformin inhibits cytokine-induced nuclear factor $\mathrm{kB}$ activation via AMP- activated protein kinase activation in vascular endothelial cells. Hypertension 47:1183-1188

44. Liu C, Liang B, Wang Q, Wu J, Zou MH (2010) Activation of AMPactivated protein kinase $\alpha 1$ alleviates endothelial cell apoptosis by increasing the expression of anti-apoptotic proteins $\mathrm{Bcl}-2$ and survivin. J Biol Chem 285:15346-15355

45. Cacicedo JM, Yagihashi N, Keaney JF Jr, Ruderman NB, Ido Y (2004) AMPK inhibits fatty acid-induced increases in NF-KB transactivation in cultured human umbilical vein endothelial cells. Biochem Biophys Res Commun 324:1204-1209

46. Bair AM, Thippegowda PB, Freichel M, Cheng N, Ye RD, Vogel SM, Yu Y, Flockerzi V, Malik AB, Tiruppathi C (2009) Ca2+ entry via TRPC channels is necessary for thrombin-induced NF-kB activation in endothelial cells through AMP-activated protein kinase and protein kinase C $\delta$. J Biol Chem 284:563-574

47. Huang NL, Chiang SH, Hsueh CH, Liang YJ, Chen YJ, Lai LP (2009) Metformin inhibits TNF- $\alpha$-induced IkB kinase phosphorylation, I $\mathrm{KB}-\alpha$ degradation and IL- 6 production in endothelial cells through PI3K-dependent AMPK phosphorylation. Int J Cardiol 134:169-175

48. Katerelos M, Mudge SJ, Stapleton D, Auwardt RB, Fraser SA, Chen CG, Kemp BE, Power DA (2010) 5-aminoimidazole-4carboxamide ribonucleoside and AMP-activated protein kinase inhibit signalling through NF-kB. Immunol Cell Biol 88:754 760

49. Ruderman NB, Xu XJ, Nelson L, Cacicedo JM, Saha AK, Lan F, Ido Y (2010) AMPK and SIRT1: a long-standing partnership? Am J Physiol Endocrinol Metab 298:E751-760

50. Canto C, Gerhart-Hines Z, Feige JN, Lagouge M, Noriega L, Milne JC, Elliott PJ, Puigserver P, Auwerx J (2009) AMPK regulates energy expenditure by modulating $\mathrm{NAD}+$ metabolism and SIRT1 activity. Nature 458:1056-1060

51. Lan F, Cacicedo JM, Ruderman N, Ido Y (2008) SIRT1 modulation of the acetylation status, cytosolic localization, and activity of LKB1. Possible role in AMP-activated protein kinase activation. J Biol Chem 283:27628-27635

52. Yeung F, Hoberg JE, Ramsey CS, Keller MD, Jones DR, Frye RA, Mayo MW (2004) Modulation of NF-kB-dependent transcription and cell survival by the SIRT1 deacetylation. EMBO J 23:2369-2380

53. Yang XD, Tajkhorshid E, Chen LF (2010) Functional interplay between acetylation and methylation of RelA subunit of NF-kB. Mol Cell Biol 30:2170-2180

54. Schug TT, Xu Q, Gao H, Peres-da-Silva A, Draper DW, Fessler MB, Purushotham A, Li X (2010) Myeloid deletion of SIRT1 induces inflammatory signaling in response to environmental stress. Mol Cell Biol 30:4712-4721

55. Yang SR, Wright J, Bauter M, Seweryniak K, Kode A, Rahman I (2007) Sirtuin regulates cigarette smoke-induced proinflammatory mediator release via RelA/p65 NF- $\mathrm{kB}$ in macrophages in vitro and in rat lungs in vivo: implications for chronic inflammation and aging. Am J Physiol Lung Cell Mol Physiol 292:L567-576

56. Chung S, Yao H, Caito S, Hwang JW, Arunachalam G, Rahman I (2010) Regulation of SIRT1 in cellular functions: role of polyphenols. Arch Biochem Biophys 501:79-90

57. Salminen A, Kauppinen A, Suuronen T, Kaarniranta K (2008) SIRT1 longevity factor suppresses NF-kB-driven immune responses: regulation of aging via NF- $\mathrm{KB}$ acetylation? BioEssays 29:939-942

58. Jeninga EH, Schoonjans K, Auwerx J (2010) Reversible acetylation of PGC- $1 \alpha$ : connecting energy sensors and effectors to guarantee metabolic flexibility. Oncogene 29:4617-4624

59. Alvarez-Guardia D, Palomer X, Coll T, Davidson MM, Chan TO, Feldman AM, Laguna JC, Vazquez-Carrera M (2010) The p65 subunit of NF- $\mathrm{kB}$ binds to PGC- $1 \alpha$, linking inflammation 
and metabolic disturbances in cardiac cells. Cardiovasc Res $87: 449-458$

60. Morari J, Torsoni AS, Anhe GF, Roman EA, Cintra DE, Ward LS, Bordin S, Velloso LA (2010) The role of proliferatoractivated receptor $\gamma$ coactivator- $1 \alpha$ in the fatty-acid-dependent transcriptional control of interleukin-10 in hepatic cells of rodents. Metab Clin Exp 59:215-223

61. Kim HJ, Park KG, Yoo EK, Kim YH, Kim YN, Kim HS, Kim HT, Park JY, Lee KU, Jang WG, Kim JG, Kim BW, Lee IK (2007) Effects of PGC- $1 \alpha$ on TNF- $\alpha$-induced MCP-1 and VCAM-1 expression and NF- $\mathrm{KB}$ activation in human aortic smooth muscle and endothelial cells. Antioxid Redox Signal 9:301-307

62. Palomer X, Alvarez-Guardia D, Rodriguez-Calvo R, Coll T, Laguna JC, Davidson MM, Chan TO, Feldman AM, VazquezCarrera M (2009) TNF- $\alpha$ reduces PGC- $1 \alpha$ expression through $\mathrm{NF}-\mathrm{kB}$ and $\mathrm{p} 38 \mathrm{MAPK}$ leading to increased glucose oxidation in a human cardiac cell model. Cardiovasc Res 81:703-712

63. Vousden KH, Ryan KM (2009) p53 and metabolism. Nat Rev Cancer 9:691-700

64. Nakae J, Oki M, Cao Y (2008) The FoxO transcription factors and metabolic regulation. FEBS Lett 582:54-67

65. Peng SL (2008) Foxo in the immune system. Oncogene 27:23372344

66. Komarova EA, Krivokrysenko V, Wang K, Neznanov N, Chernov MV, Komarov PG, Brennan ML, Golovkina TV, Rokhlin OW, Kuprash DV, Nedospasov SA, Hazen SL, Feinstein E, Gudkov AV (2005) p53 is a suppressor of inflammatory response in mice. FASEB J 19:1030-1032

67. Jones RG, Plas DR, Kubek S, Buzzai M, Mu J, Xu Y, Birnbaum MJ, Thompson CB (2005) AMP-activated protein kinase induces a p53-dependent metabolic checkpoint. Mol Cell 18:283-293

68. Ak P, Levine AJ (2010) p53 and NF-kB: different strategies for responding to stress lead to a functional antagonism. FASEB J 24:3643-3652

69. Salminen A, Kaarniranta K (2011) Control of p53 and NF-kB signaling by WIP1 and MIF: role in cellular senescence and organismal aging. Cell Signal 23:747-752

70. Kawauchi K, Araki K, Tobiume K, Tanaka N (2008) p53 regulates glucose metabolism through an IKK-NF- $\mathrm{KB}$ pathway and inhibits cell transformation. Nat Cell Biol 10:611-618

71. Kawauchi K, Araki K, Tobiume K, Tanaka N (2009) Loss of p53 enhances catalytic activity of IKKß through O-linked B-N-acetyl glucosamine modification. Proc Natl Acad Sci USA 106:34313416

72. Maclaine NJ, Hupp TR (2009) The regulation of p53 by phosphorylation: a model for how distinct signals integrate into the p53 pathway. Aging 1:490-501

73. Goodman JE, Hofseth LJ, Hussain SP, Harris CC (2004) Nitric oxide and p53 in cancer-prone chronic inflammation and oxyradical overload disease. Environ Mol Mutagen 44:3-9

74. Greer EL, Dowlatshahi D, Banko MR, Villen J, Hoang K, Blanchard D, Gygi SP, Brunet A (2007) An AMPK-FOXO pathway mediates longevity induced by a novel method of dietary restriction in C. elegans. Curr Biol 17:1646-1656

75. Greer EL, Oskoui PR, Banko MR, Maniar JM, Gygi MP, Gygi SP, Bruner A (2007) The energy sensor AMP-activated protein kinase directly regulates the mammalian $\mathrm{FOXO} 3$ transcription factor. J Biol Chem 282:30107-30119

76. Lin L, Hron JD, Peng SL (2004) Regulation of NF-kB, Th activation, and autoinflammation by the forkhead transcription factor Foxo3a. Immunity 21:203-213

77. Zhou W, Cao Q, Peng Y, Zhang QJ, Castrillon DH, Depinho RA, Liu ZP (2009) FoxO4 inhibits NF-kB and protects mice against colonic injury and inflammation. Gastroenterology 137:1403-1414

78. Kobayashi Y, Furukawa-Hibi Y, Chen C, Horio Y, Isobe K, Ikeda K, Motoyama N (2005) SIRT1 is critical regulator of
FOXO-mediated transcription in response to oxidative stress. Int J Mol Med 16:237-243

79. Li XN, Song J, Zhang L, LeMaire SA, Hou X, Zhang C, Coselli JS, Chen L, Wang XL, Zhang Y, Shen YH (2009) Activation of the AMPK-FOXO3 pathway reduces fatty acid-induced increase in intracellular reactive oxygen species by upregulating thioredoxin. Diabetes 58:2246-2257

80. Xie Z, Zhang J, Wu J, Viollet B, Zou MH (2008) Upregulation of mitochondrial uncoupling protein-2 by the AMP-activated protein kinase in endothelial cells attenuates oxidative stress in diabetes. Diabetes 57:3222-3230

81. Schulze PC, Yoshioka J, Takahashi T, He Z, King GL, Lee RT (2004) Hyperglycemia promotes oxidative stress through inhibition of thioredoxin function by thioredoxin-interacting protein. $\mathrm{J}$ Biol Chem 279:30369-30374

82. Schroder M (2005) The mammalian unfolded protein response. Annu Rev Biochem 74:739-789

83. Dong Y, Zhang M, Wang S, Liang B, Zhao Z, Liu C, Wu M, Choi HC, Lyons TJ, Zou MH (2010) Activation of AMPactivated protein kinase inhibits oxidized LDL-triggered endoplasmic reticulum stress in vivo. Diabetes 59:1386-1396

84. Terai K, Hiramoto Y, Masaki M, Sugiyama S, Kuroda T, Hori M, Kawase I, Hirota H (2005) AMP-activated protein kinase protects cardiomyocytes against hypoxic injury through attenuation of endoplasmic reticulum stress. Mol Cell Biol 25:9554-9575

85. Dong Y, Zhang M, Liang B, Xie Z, Zhao Z, Asfa S, Choi HC, Zou MH (2010) Reduction of AMP-activated protein kinase $\alpha 2$ increases endoplasmic reticulum stress and atherosclerosis in vivo. Circulation 121:792-803

86. Zhang BB, Zhou G, Li C (2009) AMPK: an emerging drug target for diabetes and the metabolic syndrome. Cell Metab 9:407-416

87. Zhou G, Sebhat IK, Zhang BB (2009) AMPK activatorspotential therapeutics for metabolic and other diseases. Acta Physiol 196:175-190

88. Fisslthaler B, Fleming I (2011) Activation and signaling by the AMP-activated protein kinase in endothelial cells. Circ Res. doi:10.1161/CIRCRESAHA.109.201590

89. Wong AKF, Howie J, Petrie JR, Lang CC (2009) AMP-activated protein kinase pathway: a potential therapeutic target in cardiometabolic disease. Clin Sci 116:607-620

90. Shackelford DB, Shaw RJ (2009) The LKB1-AMPK pathway: metabolism and growth control in tumous suppression. Nat Rev Cancer 9:563-575

91. Wu Y, Song P, Xu J, Zhang M, Zou MH (2007) Activation of protein phosphatase $2 \mathrm{~A}$ by palmitate inhibits AMP-activated protein kinase. J Biol Chem 282:9777-9788

92. Herranz D, Serrano M (2010) SIRT1: recent lessons from mouse models. Nat Rev Cancer 10:819-823

93. Luo Z, Zang M, Guo W (2010) AMPK as a metabolic tumor suppressor: control of metabolism and cell growth. Future Oncol 6:457-470

94. Lopez-Lluch G, Irusta PM, Navas P, de Cabo R (2008) Mitochondrial biogenesis and healthy aging. Exp Gerontol 43:813-819

95. Zhang Q, Raoof M, Chen Y, Sumi Y, Sursal T, Junger W, Brohi K, Itagaki K, Hauser CJ (2010) Circulating mitochondrial DAMPs cause inflammatory responses to injury. Nature 464:104-107

96. Zhang Z, Lowry SF, Guarente L, Haimovich B (2010) Roles of SIRT1 in the acute and restorative phases following induction of inflammation. J Biol Chem 285:41391-41401

97. Zhou R, Yazdi AS, Menu P, Tschopp J (2011) A role for mitochondria in NLRP3 inflammasome activation. Nature 469:221-225

98. Horng T, Hotamisligil GS (2011) Linking the inflammasome to obesity-related disease. Nat Med 17:164-165 
99. Martinon F, Mayor A, Tschopp J (2009) The inflammasomes: guardians of the body. Annu Rev Immunol 27:229-265

100. Egan DF, Shackelford DB, Mihaylova MM, Gelino S, Kohnz RA, Mair W, Vasquez DS, Joshi A, Gwinn DM, Taylor R, Asara JM, Fitzpatrick J, Dillin A, Viollet B, Kundu M, Hansen M, Shaw RJ (2011) Phosphorylation of ULK1 (hATG1) by AMPactivated protein kinase connects energy sensing to mitophagy. Science 331:456-461

101. Hattori Y, Nakano Y, Hattori S, Tomizawa A, Inukai K, Kasai K (2008) High molecular weight adiponectin activates AMPK and suppresses cytokine-induced NF- $\mathrm{KB}$ activation in vascular endothelial cells. FEBS Lett 582:1719-1724

102. Sahra IB, Le Marchand-Brustel Y, Tanti JF, Bost F (2010) Metformin in cancer therapy: a new perspective for an old antidiabetic drug? Mol Cancer Ther 9:1092-1099

103. Franceschi C, Valensin S, Bonafè M, Paolisso G, Yashin AI, Monti D, De Benedictis G (2000) The network and the remodeling theories of aging: historical background and new perspectives. Exp Gerontol 35:879-896

104. Salminen A, Huuskonen J, Ojala J, Kauppinen A, Kaarniranta K, Suuronen T (2008) Activation of innate immunity system during aging: NF- $\mathrm{KB}$ signaling is the molecular culprit of inflamm-aging. Ageing Res Rev 7:83-105

105. de Magalhaes JP, Curado J, Church GM (2009) Meta-analysis of age-related gene expression profiles identifies common signatures of aging. Bioinformatics 25:875-881

106. Adler AS, Sinha S, Kawahara TL, Zhang JY, Segal E, Chang HY (2007) Motif module map reveals enforcement of aging by continual NF-kB activity. Genes Dev 21:3244-3257

107. Salminen A, Kaarniranta K (2009) NF- $K B$ signaling in the aging process. J Clin Immunol 29:397-405

108. Turdi S, Fan X, Li J, Zhao J, Huff AF, Du M, Ren J (2010) AMPactivated protein kinase deficiency exacerbates aging-induced myocardial contractile dysfunction. Aging Cell 9:592-606
109. Reznick RM, Zong H, Li J, Morino K, Moore IK, Yu HJ, Liu ZX, Dong J, Mustard KJ, Hawley SA, Befroy D, Pypaert M, Hardie DG, Young LH, Shulman GI (2007) Aging-associated reductions in AMPK-activated protein kinase activity and mitochondrial biogenesis. Cell Metab 5:151-156

110. Qiang W, Weiqiang K, Qing Z, Pengju Z, Yi L (2007) Aging impairs insulin-stimulated glucose uptake in rat skeletal muscle via suppressing AMPK $\alpha$. Exp Mol Med 39:535-543

111. Curtis R, O'Connor G, DiStefano PS (2006) Aging networks in Caenorhabditis elegans: AMP-activated protein kinase (aak-2) links multiple aging and metabolism pathways. Aging Cell 5:119-126

112. Narbonne P, Roy R (2009) Caenorhabditis elegans dauers need LKB1/AMPK to ratio lipid reserves and ensure long-term survival. Nature 457:210-214

113. Selman C, Tullet JMA, Wieser D, Irvine E, Lingard SJ, Choudhury AI, Claret M, Al-Qassab H, Carmignac D, Ramadani F, Woods A, Robinson ICA, Schuster E, Batterham RL, Kozma SC, Thomas G, Carling D, Okkenhaug K, Thornton JM, Partridge L, Gems D, Withers DJ (2009) Ribosomal protein S6 kinase 1 signaling regulates mammalian life span. Science 326:140-144

114. Salminen A, Kaarniranta K (2009) Regulation of the aging process by autophagy. Trends Mol Med 15:217-224

115. Salminen A, Kaarniranta K (2009) SIRT1: regulation of longevity via autophagy. Cell Signal 21:1356-1360

116. Bauer JA, Pearson KJ, Price NL, Jamieson HA, Lerin C, Kalra A, Prabhu VV, Allard JS, Lopez-Lluch G, Lewis K, Pistell PJ, Poosala A, Becker KG, Boss O, Gwinn D, Wang M, Ramaswamy S, Fishbein KW, Spencer RG, Lakatta EG, Le Couteur D, Shaw RJ, Navas P, Puigserver P, Ingram DK, de Cabo R, Sinclair DA (2006) Resveratrol improves health and survival of mice on a high-calorie diet. Nature 444:337-342

117. Salminen A, Kaarniranta K (2010) Genetics vs. entropy: longevity factors suppress the NF- $\mathrm{KB}$-driven entropic aging process. Ageing Res Rev 9:298-314 